\title{
Perancangan dan Simulasi Microring Resonator Optik dengan Variasi Indeks Bias Cladding untuk Aplikasi Sensor Amonia pada Air Tambak
}

\author{
Fahmi Juliansyah $^{1 *}$, Gandi Sugandi², dan Lilik Hasanah ${ }^{1}$ \\ ${ }^{1}$ Program Studi Fisika, Universitas Pendidikan Indonesia, Jl. Dr. Setiabudhi 229 Bandung 40154, \\ Indonesia \\ ${ }^{2}$ Pusat Penelitian Elektronika dan Telekomunikasi, Lembaga Ilmu Pengetahuan Indonesia, Jl. \\ Sangkuriang, Komplek LIPI, Gd. 20, Cisitu, Dago, Coblong, Kota Bandung 40135, Indonesia, \\ *Corresponding author.E-mail:fjuliansyah@gmail.com \\ Telp: +6285974708130
}

\begin{abstract}
ABSTRAK
Kualitas air merupakan faktor yang sangat penting dalam budidaya perikanan. Salah satu faktor yang mempengaruhi kualitas air adalah konsentrasi amonia. Oleh karena itu dalam budi daya perikanan dibutuhkan sensor amonia untuk memantau konsentrasi amonia. Sensor berbasis optical microring resonator optik (MRRO) telah menarik banyak perhatian karena ukurannya yang sangat kecil dan sensitifitasnya yang lebih tinggi dibandingkan sensor lain. Dalam penelitian ini telah dirancang dan disimulasikan sensor amonia berbasis MRRO dengan jari-jari ring $5 \mu \mathrm{m}$, lebar waveguide $0,1 \mu \mathrm{m}$ dan gap $0,1 \mu \mathrm{m}$. Sensor menunjukkan linearitas yang sangat baik dengan sensitifitas sensor sebesar 168,82 nm/RIU (refractive index unit) dan 0,0973 $\mathrm{nm} / \%$ amonia dalam air, dan batas deteksi $0,1 \%$ konsentrasi amonia dalam air.
\end{abstract}

Kata Kunci: amonia; analisis elemen hingga; optical microring resonator; sensor optik.

\begin{abstract}
Water quality is a very important factor in aquaculture. One of the factor that determines water quality is ammonia concentration. Therefore, in aquaculture ammonia sensor is needed to monitor ammonia concentration. Optical microring-resonator(OMRR)-based sensors have gained a lot of interest because of it's small size and higher sensitivity compared to other sensors. In this research, an OMRR-based ammonia sensor with ring radius of $5 \mu \mathrm{m}$, waveguide width of $0,1 \mu \mathrm{m}$, and gap of $0,1 \mu \mathrm{m}$ has been designed and simulated. The sensor showing a very good linearity with sensor's sensitivity of $168,82 \mathrm{~nm} / \mathrm{RIU}$ (refractive index unit) and $0,0973 \mathrm{~nm} / \%$ ammonia in the water, and detection limit of $0,1 \%$ ammonia on the water.
\end{abstract}

Keywords: ammonia; finite element analysis; optical microring resonator; optical sensor 


\section{Pendahuluan}

Budi daya perikanan adalah sektor penghasil makanan yang tumbuh paling cepat di dunia, dengan tingkat pertumbuhan tahunan rata-rata $8,9 \%$ sejak tahun 1970 [1]. Pengembangan budidaya perikanan masih dihadapkan pada permasalahan (1) implementasi kebijakan tata ruang dan rencana zonasi pada wilayah pesisir dan pulau-pulau kecil, (2) terbatasnya prasarana saluran irigasi, (3) terbatasnya ketersediaan dan distribusi untuk induk dan benih unggul, (4) kesiapan dalam menanggulangi hama dan penyakit, (5) penyediaan fasilitas kolam dan air yang baik, (6) permasalahan bahan baku pakan dan kestabilan harga, serta (7) tingginya harga pakan. Rendahnya produktifitas perikanan budidaya juga disebabkan karena struktur pelaku usaha budidaya perikanan adalah skala kecil/tradisional $( \pm 80 \%)$, dengan keterbatasan aspek permodalan, jaringan teknologi, dan pasar. Selain itu serangan hama dan penyakit ikan/udang, serta adanya pencemaran yang mempengaruhi kualitas lingkungan perikanan budidaya [2].

Kualitas air merupakan faktor yang sangat penting dalam budi daya perikanan. Kualitas air dapat membuat ikan lebih tahan terhadap serangan hama dan penyakit. Selain itu kualitas air yang baik akan meningkatkan produktivitasnya. Faktor-faktor yang berpengaruh terhadap kulitas air pada budidaya perikanan adalah kandungan oksigen, salinitas, $\mathrm{pH}$, temperatur dan kadar amonia $\left(\mathrm{NH}_{3}\right)$ [3]

Amonia adalah produk akhir metabolisme nitrogen yang bersifat racun [4]. Amonia meningkatkan konsumsi oksigen jaringan, merusak insang dan mengurangi kemampuan darah untuk mengangkut oksigen [5]. Amonia ada di air dalam bentuk terionisasi $\left(\mathrm{NH}_{4}^{+}\right)$dan tak terionisasi $\left(\mathrm{NH}_{3}\right)$.

$\mathrm{NH}_{3}$ adalah bentuk amonia yang paling beracun karena kemampuannya untuk berdifusi dengan mudah melintasi membran sel [6]. kriteria kadar amonia dalam budidaya ikan salmon, diperlihatkan pada Tabel 1 [7]. Oleh karena itu diperlukan sensor amonia untuk keperluan budi daya perikanan.
Table 1. Kriteria kadar amonia (mg/l) dalam sistem budidaya ikan salmon

\begin{tabular}{ccc}
\hline Tingkat (level) & $\begin{array}{c}\mathrm{NH}_{3} \\
\left(\mathrm{mg} / 1^{*}\right)\end{array}$ & $\begin{array}{c}\mathrm{NH}_{4}{ }^{+} \\
\left(\mathrm{mg} / 1^{*}\right)\end{array}$ \\
\hline Optimum & 0 & $<0,4$ \\
Diinginkan & $<0,005$ & $<1,0$ \\
$\begin{array}{c}\text { Diperbolehkan } \\
\text { dalam periode } \\
\text { pendek }\end{array}$ & $<0,025$ & $<1,6$ \\
$\begin{array}{c}\text { Mulai mematikan } \\
* 1 \mathrm{mg} / \mathrm{l}=1 \mathrm{ppm}\end{array}$ & 0,08 & 3,0 \\
\hline
\end{tabular}

Saat ini Reaksi Nessler adalah salah satu metode deteksi yang mudah ditemukan dan sering digunakan untuk menentukkan konsentrasi total amonia dalam air [8]. Metode ini menggunakan reagent Nessler, yaitu $\mathrm{K}_{2} \mathrm{HgI}_{4}$ (dipotassium tetraiodomercurate(II)), yang dicampur dengan larutan alkaline encer, biasanya $\mathrm{NaOH}$ (natrium hidroksida) [9]. Reagent ini bersifat beracun. Selain itu kelemahan kedua metode ini adalah produk sampingan reaksi berupa $\mathrm{Hg}\left(\mathrm{NH}_{2}\right) \mathrm{I}$ (mercury(II) amidoiodide) yang bersifat tidak dapat larut dalam air, sehingga metode ini sulit diterapkan dalam sistem deteksi miniatur [8].

Metode lainnya yang tengah berkembang adalah sensor berbasis microring resonator optik (MRRO). Sensor ini telah menarik banyak perhatian karena ukurannya yang sangat kecil dibandingkan sensor jenis lain [10]. Selain itu MRRO telah menunjukkan potensi yang besar dalam komunikasi optikal dan sensor photonik karena ukurannya yang ringkas, performa yang baik, sensitifitas yang tinggi dan biaya pembuatan yang rendah [11]. Oleh karena itu, pada penelitian kali ini akan dilakukan perancangan dan simulasi devais sensor amonia berbasis microring resonator optik yang ringkas, dan sensitif.

Sensor adalah suatu devais yang mengubah suatu fenomena fisik menjadi sinyal listrik [12]. Yang dimaksud "listrik' adalah sinyal yang dapat disalurkan, diamplifikasi, dan diubah oleh perangkat elektronik. Salah satu jenis sensor adalah sensor optik. 
Sensor optik adalah devais pengukur di mana kuantitas yang diukur diubah menjadi optis dan, kemudian, menjadi sinyal listrik dengan menggunakan transduser optoelektronik [13]. Salah satu fitur sensor optik adalah kemampuannya untuk mengukur perubahan berkas cahaya. Perubahan tersebut biasanya perubahan terhadap intensitas cahaya [14]. Salah satu jenis sensor optik adalah sensor fiber optik.

Sensor fiber optik adalah sensor yang menggunakan serat optik baik sebagai elemen penginderaan (sensing element) (pada sensor intrinsik) atau sebagai alat untuk me'relay' sinyal dari remote sensor kepada elektronika yang dapat memproses sinyal (pada sensor ekstrinsik) [14]. Ide dasar dari penggunaan fiber optik dalam sensing adalah untuk memodulasi satu atau beberapa karakteristik dari cahaya di dalam suatu fiber dan, kemudian, mendemodulasikan informasi secara optik dengan metode konvensional [15]. Keuntungan yang melekat pada sensor fiber optik, yang meliputi (1) bobot yang ringan, ukuran sangat kecil, pasif, daya rendah, tahan terhadap interferensi elektromagnetik, sensitivitasnya yang tinggi, (3) bandwidthnya, dan (4) ketahanan terhadap lingkungan [16].

Microring resonator optik (MRRO) adalah suatu perangkat waveguide yang terdiri dari waveguide optik lurus dan berbentuk loop tertutup (dapat berbentuk ring, sehingga pada umumnya disebut microring resonator) yang dihubungkan dengan sumber input dan output cahaya [14]. Konfigurasi dasar MRRO terdiri dari satu waveguide ring berjari-jari $r$ yang ter kopel dengan satu waveguide lurus atau yang biasa disebut all-pass microring resonator seperti ditunjukkan oleh Gambar 1.

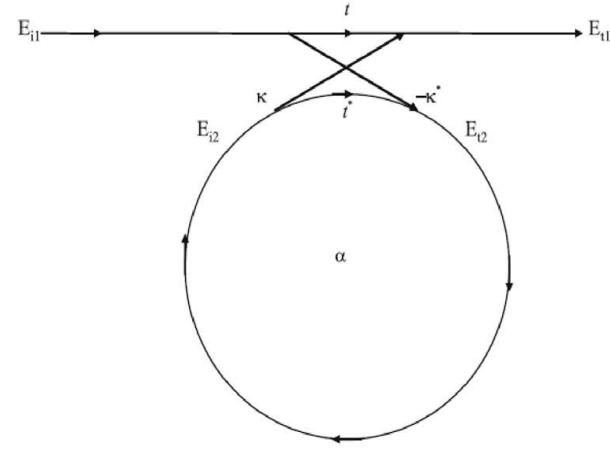

Gambar 1. All-pass microring resonator [17]

Prinsip kerja MRRO adalah ketika cahaya merambat pada waveguide lurus, sebagian cahaya tersebut akan terrefraksi keluar menuju daerah cladding [18] menjadi gelombang evanescent [19]. Gelombang evanescent yang berada di gap sebagian terkopel ke waveguide ring dan dipandu mengelilingi ring [20]. Gelombang pada ring kemudain akan terrefraksi juga keluar dari ring dan sebagian akan terkopel kempali pada waveguide lurus, dan berinterferensi dengan gelombang yang diteruskan oleh waveguide lurus dari input. Namun hanya panjang gelombang yang memenuhi persamaan (1) yang menghasilkan resonansi [14].

$$
\lambda_{\text {res }}=\frac{n_{e f f} L}{m}
$$

Di mana $\lambda_{\text {res }}$ adalah panjang gelombang resonansi, $\mathrm{n}_{\text {eff }}$ adalah indeks bias efektif, $\mathrm{L}$ adalah keliling MRRO, dan $\mathrm{m}$ adalah orde mode resonansi ( $\mathrm{m}$ adalah bilangan bulat). Jika persamaan (1) tidak terpenuhi maka MRRO akan berada pada keadaan off resonance dimana gelombang yang dipandu akan melewati ring dan tidak masuk ke ring dan keluar melalui port output [21]. Spektrum transmisi dari MRRO pada umumnya ditunjukkan oleh Gambar 2 


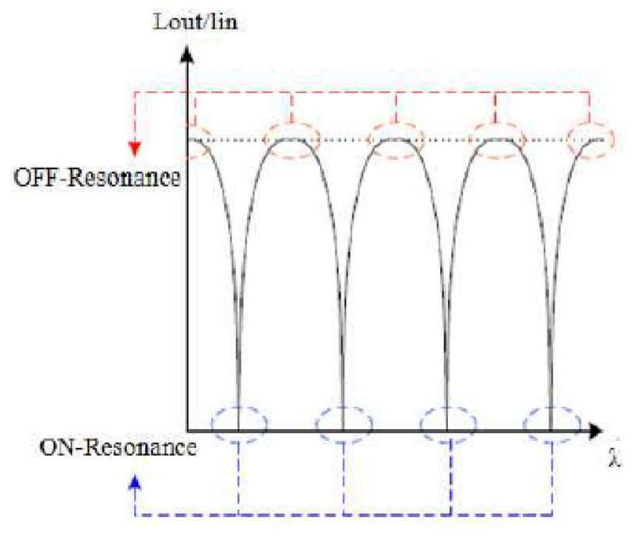

Gambar 2 Spektrum transmisi MRRO all-pass [22]

Filter MRRO memiliki beberapa parameter yang dapat mendeskripsikannya yang mana juga digunakan untuk mendeskripsikan filter optik. Parameter-parameter tersebut adalah Free Spectral Range (FSR), Full-width at HalfMaximum (FWHM), Finesse, dan Q-Factor.

FSR adalah lebar daerah passband yang dihasilkan oleh filter MRRO [20]. Secara teori FSR MRRO dapat dihitung dengan rumus: [15]

$$
F S R=\frac{\lambda_{r e s}^{2}}{n_{e f f} L}
$$

FSR pada spektrum output bisa dianggap rentang pengukuran pada sensor microring [23]. FSR pada spektrum transmisi MRRO digambarkan pada Gambar 3

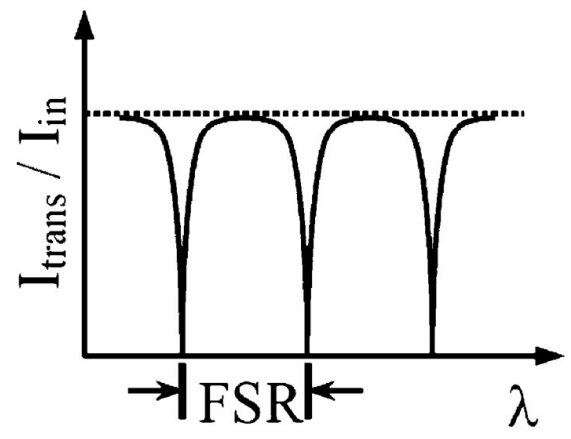

Gambar 3 FSR pada spektrum transmisi MRRO. [24]

FWHM adalah rentang panjang gelombang (yaitu bandwidth) di mana filter mentransmisikan setidaknya 50\% dari puncak transmisinya [25]. Nilai FWHM diukur pada $3 \mathrm{~dB}$ da didaerah frekuensi kerja [18]. Secara teori FWHM MRRO dapat dihitung dengan rumus [15]

$$
F W H M=\frac{K^{2} \lambda_{r e s}{ }^{2}}{n_{e f f} L \pi}
$$

Dimana $\mathrm{K}$ adalah parameter kopling MRRO. FWHM pada spektrum transmisi MRRO digambarkan pada Gambar 2.12. FSR harus lebih besar dari FWHM untuk menghindari kerancuan pada puncak resonansi [26].

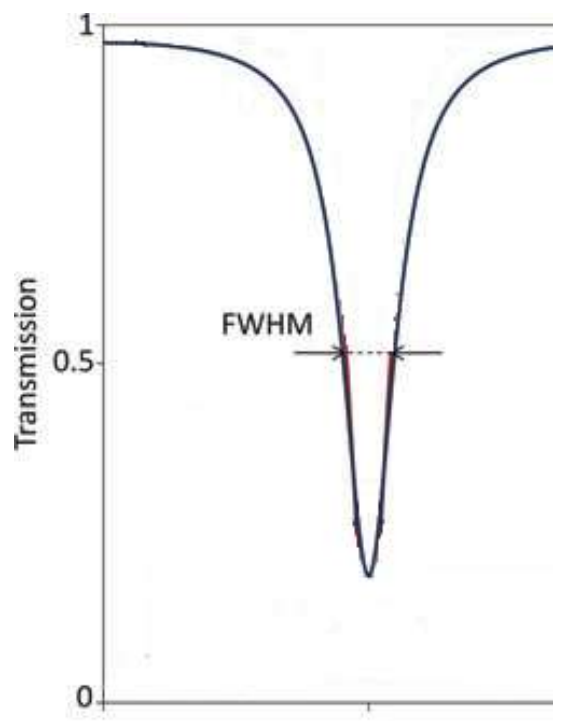

Gambar 2. 1 FWHM pada spektrum transmisi MRRO [27]

Setelah mendapatkan nilai FSR dan FWHM kita dapat menghitung Finesse. Finesse dapat didefinisikan sebagai rasio antara nilai FSR dengan nilai FWHM (Persamaan (4)) [15]. Dengan kata lain Finesse adalah ukuran seberapa banyak puncak FWHM yang bisa diatur pada sensor tanpa berhadapan dengan mode lain yang dapat menyebabkan sinyal output yang rancu [28].

$$
\text { Finesse }=\frac{F S R}{F W H M}
$$


Setelah mendapatkan nilai Finesse kita dapat menghitung nilai Q-Factor. Sensitifitas sensor MRRO ditentukan oleh Q-factor dari MRRO [24]. Q-factor didefinisikan sebagai rasio antara panjang gelombang operasi dan lebar resonansi [15];

$$
Q=\frac{n_{e f f} L}{\lambda_{\text {res }}} F
$$

Dan dari persamaan (2), (3), dan (5), maka;

$$
Q=\frac{\lambda_{\text {res }}}{F W H M}
$$

Dimana Q adalah Q-factor MRRO.Sehingga dengan mengetahui Finesse dan Q-factor dari suatu perangkat optik dapat diperkirakan pula FSR dan FWHM pada frekuensi kerja tertentu dari perangkat optik tertentu.

\section{Metode}

\subsection{Prinsip Kerja Sensor}

Perubahan konsentrasi amonia menyebabkan perubahan indeks bias cladding. Perubahan indeks bias cladding menyebabkan perubahan indeks bias efektif $\left(\mathrm{n}_{\mathrm{eff}}\right)$ [29]. Sedangkan panjang gelombang resonansi dipengaruhi oleh indeks bias efektif dengan persamaan [30]. Oleh karena itu perubahan konsentrasi amonia dapat menyebabkan pergeseran panjang gelombang resonansi MRRO yang ditunjukkan pada Gambar 4.

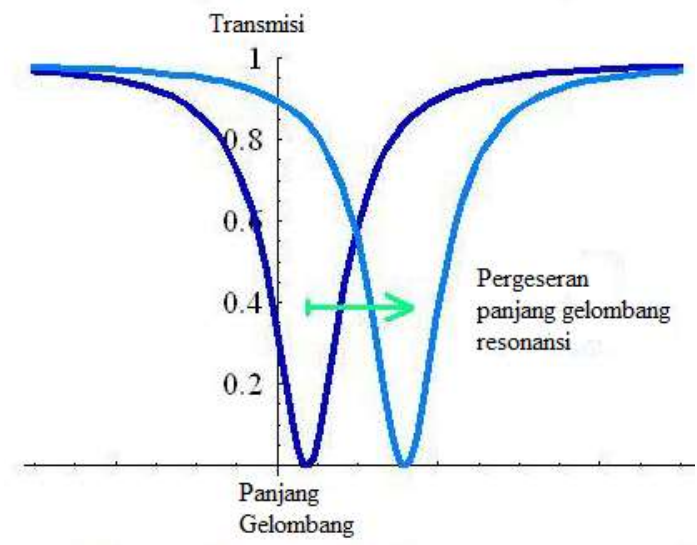

Gambar 4 Pergeseran panjang gelombang resonansi akibat perubahan konsentrasi amonia [29]

\subsection{Desain MRRO}

Desain geometri MRRO ditunjukkan oleh Gambar 2.

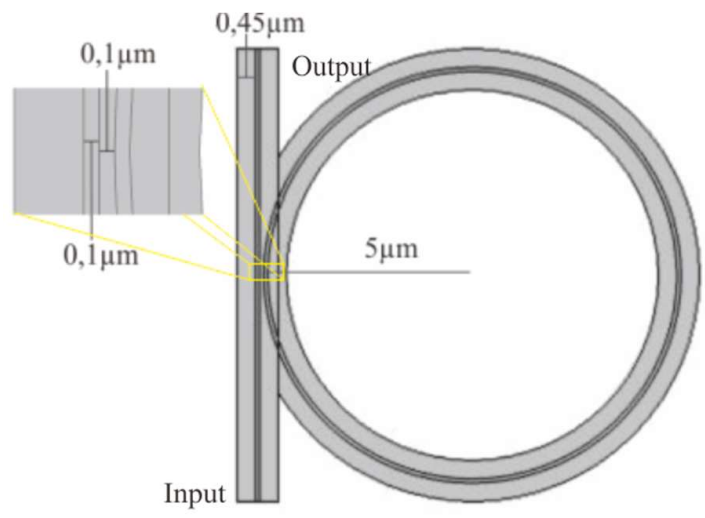

Gambar 5. Bentuk dan ukuran MRRO.

Core yang digunakan berbahan silikon $(\mathrm{Si})$ dengan indeks bias 3,48 [31]. Sedangkan bagian cladding menggunakan larutan amonia dalam air pada berbagai konsentrasi dengan indeks bias cladding yang ditunjukkan Tabel 2 [32].

Tabel 2 Indeks bias terhadap konsentrasi amonia dalam air

\begin{tabular}{cc}
\hline Persen berat (\%) & Indeks bias \\
\hline 0.00 & 1.3330 \\
0.50 & 1.3332 \\
1.00 & 1.3335 \\
1.50 & 1.3337 \\
2.00 & 1.3339 \\
2.50 & 1.3342 \\
3.00 & 1.3344 \\
3.50 & 1.3347 \\
4.00 & 1.3349 \\
4.50 & 1.3352 \\
5.00 & 1.3354 \\
5.50 & 1.3357 \\
6.00 & 1.3359
\end{tabular}


Fahmi Juliansyah, dkk. Perancangan dan Simulasi Microring Resonator Optik...

\begin{tabular}{ll}
8.00 & 1.3370 \\
10.00 & 1.3381 \\
11.00 & 1.3387 \\
15.00 & 1.3410 \\
20.00 & 1.3440 \\
26.00 & 1.3477 \\
30.00 & 1.3502 \\
\hline
\end{tabular}

\section{Hasil dan Pembahasan}

Hasil simulasi untuk S21 (dB) dari MRRO pada rentang panjang gelombang $1500 \mathrm{~nm}-$ $1600 \mathrm{~nm}$ ditunjukkan oleh Gambar 6

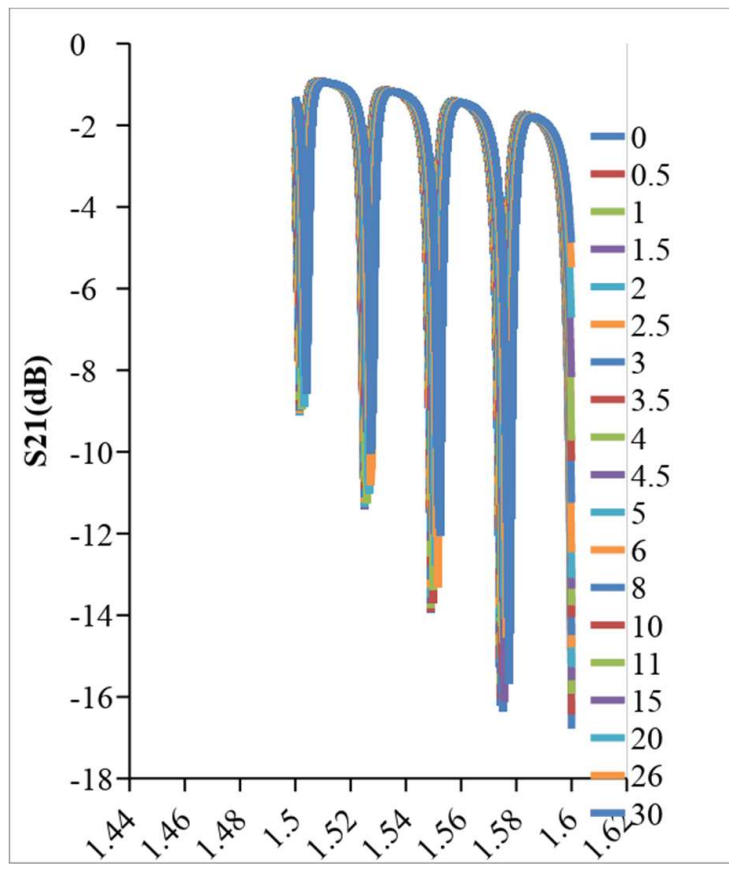

Gambar 6 Hasil simulasi MRRO pada rentang panjang gelombang $1500 \mathrm{~nm}-1600 \mathrm{~nm}$

Dari Gambar 6 didapatkan FSR dari MRRO sebesar 24,19 nm dan FWHM di resonansi 1,549193548 mikron sebesar $5,57 \mathrm{~nm}$. Sehingga Finesse dari MRRO dapat dihitung yaitu sebesar 4,34 dan Q-factor pada resonansi 1,549193548 sebesar 278,256. Karakteristik MRRO ditunjukkan pada Tabel 3 berikut.
Tabel 3 Parameter MRRO hasil simulasi

\begin{tabular}{cc}
\hline Parameter & Nilai \\
\hline FSR & $24,19 \mathrm{~nm}$ \\
FWHM & $5,57 \mathrm{~nm}$ \\
Finesse & 4,34 \\
Q-Factor & 278,256 \\
\hline
\end{tabular}

Pada grafik tersebut telah dapat dilihat kencenderungan pergeseran panjang gelombang resonansi yang semakin besar saat indeks bias diperbesar. Namun grafik tersebut kurang akurat dalam menunjukkan puncak resonansi dikarenakan resolusi pengambilan data yang kurang. Oleh karena itu selanjutnya dilakukan simulasi dengan memperkecil rentang panjang gelombang resonansi dan memfokuskan ke satu daerah puncak resonansi yaitu pada rentang 1548 $\mathrm{nm}-1554 \mathrm{~nm}$.

Hasil simulasi untuk S21 (dB) dari MRRO pada rentang panjang gelombang $1548 \mathrm{~nm}$ - $1554 \mathrm{~nm}$ ditunjukkan oleh Gambar 7.

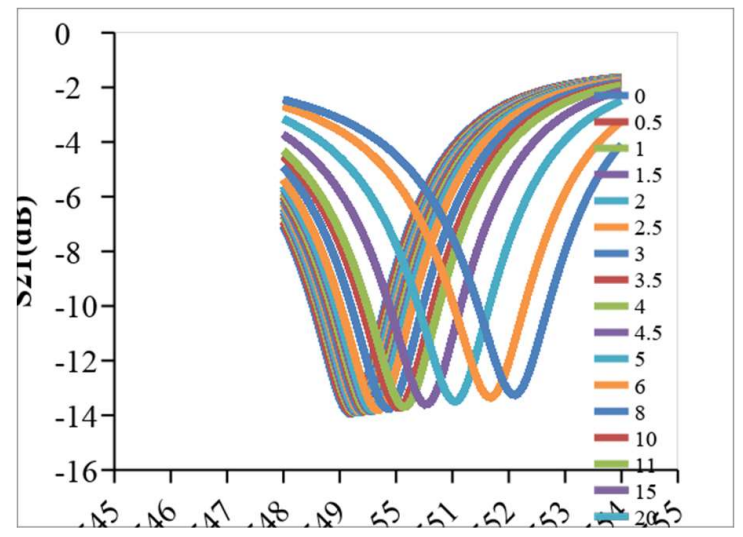

Gambar 7 Hasil simulasi untuk S21 (dB) dari MRRO pada rentang panjang gelombang 1548 $\mathrm{nm}-1554 \mathrm{~nm}$

Gambar 7 menunjukkan pergeseran panjang gelombang resonansi bergantung kepada konsentrasi yang mempengaruhi indeks bias efektif. Hal ini sesuai dengan persamaan (1).

Pengaruh indeks bias cladding, dan konsentrasi amonia di dalam air terhadap pergeseran panjang gelombang resonansi 
masing-masing ditunjukkan oleh grafik pada Gambar 8, dan Gambar 9.

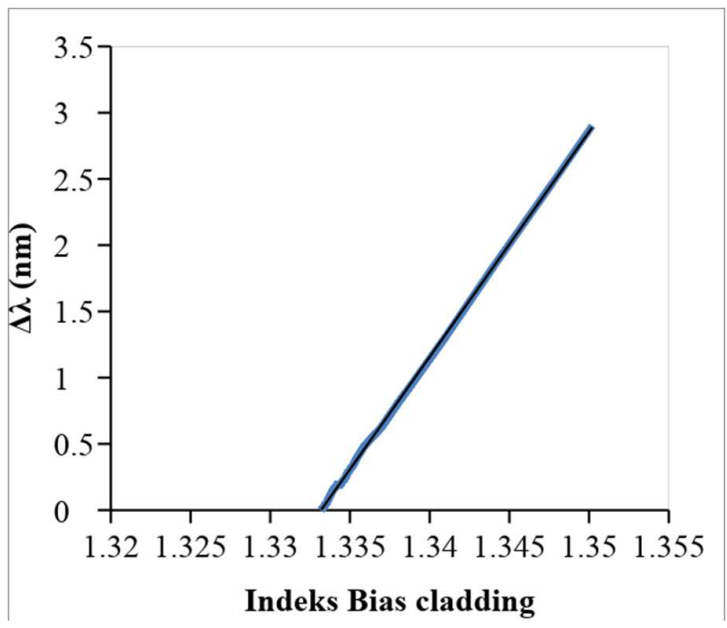

Gambar 8 Pengaruh indeks bias cladding terhadap pergeseran panjang gelombang resonansi.

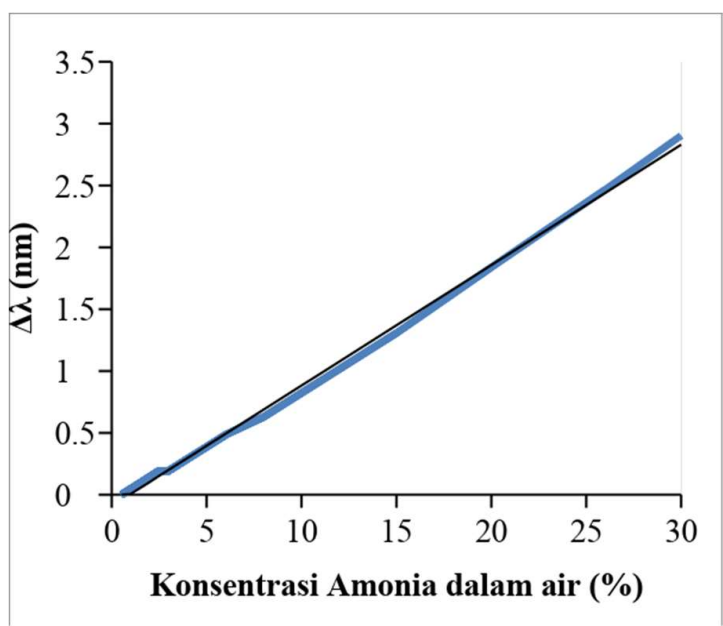

Gambar 9 Pengaruh konsentrasi amonia di dalam air terhadap pergeseran panjang gelombang resonansi.

Dari Gambar 8 dan Gambar 9 didapatkan sensitifitas sensor sebesar $169,82 \mathrm{~nm} / \mathrm{RIU}$ (Refractive Index Unit) dan 0,0973nm/\%Amonia dalam Air. Sensitifitas MRRO dan fungsi kerja sensor MRRO ditunjukkan pada Tabel 4.
Tabel 4 Sensitifitas MRRO dan fungsi kerja sensor MRRO

\begin{tabular}{ccc}
\hline Pengaruh & Sensitifitas & Fungsi Kerja \\
\hline Indeks Bias & 169,82 & $\mathrm{r}=169.82 \mathrm{n}-$ \\
& $\mathrm{nm} / \mathrm{RIU}$ & 226.4 \\
Konsentrasi & $0,0973 \mathrm{~nm} / \% \mathrm{~A}$ & $\mathrm{r}=0.0973 \mathrm{k}-$ \\
& monia & 0.0909 \\
\hline
\end{tabular}

Di mana $r$ adalah pergeseran panjang gelombang resonansi, $\mathrm{n}$ adalah indeks bias cladding, dan $\mathrm{k}$ adalah konsentrasi amonia didalam air (\%). Nilai sensitifitas ini lebih besar dari sensitifitas sensor yang didesain pada [29].

Dengan menggunakan laser yang bekerja dipanjang gelombang sekitar $1550 \mathrm{~nm}$ dan photodetector, pergeseran panjang gelombang resonansi terkecil yang dapat dideteksi sebesar 10 pm [29]. Oleh karena itu, nilai terkecil pergeseran indeks bias cladding yang dapat dideteksi adalah sebesar $5,9 \times 10^{-5}$ RIU dan perubahan konsentrasi amonia di dalam air terkecil yang dapat dideteksi adalah $0,1 \%$.

\section{Simpulan}

Telah dilakukan simulasi sensor amonia berbasis microring resonator optik menggunakan perangkat lunak COMSOL Multiphysics 5.2. berdasarkan uraian pada bagian sebelumnya dan tujuan yang ingin dicapai pada penelitian ini maka dapat diambil kesimpulan bahwa sensoramonia berbasis microring resonator yang disimulasikan pada penelitian ini memiliki memiliki free spectral range sebesar $24,19 \mathrm{~nm}$, full width at half maximum sebesar $5,57 \mathrm{~nm}$, finesse atau rasio antara FSR dengan FWHM sebesar 4,34, dan $Q$-factor sebesar 278,256, dengan sensitifitas sensor sebesar 169,82 nm/RIU (Refractive Index Unit) dan 0,0973nm/\% Amonia dalam Air, dan dapat mendeteksi perubahan indeks bias cladding sebesar $5,9 \times 10^{-5}$ RIU dan perubahan konsentrasi amonia di dalam air terkecil yang dapat dideteksi adalah $0,1 \%$. Pergeseran panjang gelombang resonansi yang terjadi sesuai dengan prediksi teori yang telah dikemukakan.

Terdapat beberapa hal menarik untuk diteliti lebih lanjut, diantaranya geometri dari 
MRRO untuk dimodifikasi kembali agar dapat menghasilkan sensor dengan kualitas yang lebih baik, material cladding yang digunakan agar menggunakan material yang dapat "memperangkap" hanya amonia di dalam cladding sehingga sensor hanya sensitif terhadap amonia dan tidak terpengaruh zat lain. Bahan yang dapat digunakan misalnya PDMS [33], dan material cladding yang digunakan agar menggunakan material yang secara optik sensitif pada amonia sehingga menghasilkan perubahan indeks bias yang lebih besar tiap perubahan konsentrasi, sehingga sensitifitas sensor MRRO terhadap konsentrasi amonia dapat meningkat. Bahan yang dapat digunakan misalnya dyes (pewarna) Bromocresol Purple (BCP) [34].

\section{Referensi}

[1] Subasinghe, R. (2005). Epidemiological approach to aquatic animal health management: opportunities and challenges for developing countries to increase aquatic production through aquaculture. Preventive Veterinary Medicine 67, 117124.

[2] Kementerian Kelautan dan Perikanan. (2015). Rencana Strategis Kementerian Kelautan Dan Perikanan 2015-2019. Indonesia.

[3] Kungvankij, P., L.B. Tiro, J., B.J. Pudadera, J., Potestas, I., Corre, K., Borlongan, E., et al. (1985). Training Manual Shrimp Hatchery Design, Operation and Management. Bangkok: Network of Aquaculture Centres in Asia.

[4] Sutomo. (1989). Pengaruh Amonia Terhadap Ikan dalam Sistem Budidaya Ikan Tertutup. Oseana, XIV(1), 19-26.

[5] Li, D., \& Liu, S. (2013). Remote Monitoring of Water Quality for Intensive Fish Culture. Smart Sensors for Real-Time Water Quality Monitoring, 217-238.

[6] Bower, C., \& Bidwell, J. (1978). Ionization of ammonia in seawater: Effects of temperature, $\mathrm{pH}$ and salinity. Journal of the Fisheries Research of Canada 35, 1012-1016.

[7] Liao, P. B., \& Mayo, R. D. (1972). Salmonid Hatchery Water Reuse Systems. Aquaculture, 317-335

[8] Timmer, B., Olthuis, W., \& Berg, A. v. (2005). Ammonia Sensors and Their
Applications-a Review. Sensors and Actuators B, 666-677.

[9] Vogel, A. I. (1979). Vogel's Textbook of Macro and Semimicro Qualitative Inorganic Analysis (Kelima ed.). (G. Svehla, Penyunt.) New York: Longman Inc.

[10] Kwon, M.-S., \& Steier, W. H. (2008, Juni 11). Microring-resonator-based sensor measuring both the concentration and temperature of a solution. OPTICS EXPRESS, 16.

[11] Muhammadi, A., Sugesti, E. S., \& Mahmudin, D. (2015, Desember). Simulasi Filter Optik Single Microring Resonator Sebagai Optical Add Drop Multiplexer. e-Proceeding of Engineering, 2(3), 7308-7314

[12] Wilson, J. (2005). Sensor Technology Handbook. Oxford: Newnes.

[13] Ripka, P., \& Tipek, A. (2007). Modern sensors handook. London: ISTE Ltd.

[14] Mulyanti, B., Hasanah, L., P, A. B., \& Budi, A. H. (2016, Mei). Desain dan Fabrikasi Sistem Sensor Optik Terintegrasi Berbasis Polimer untuk Aplikasi Budidaya Perikanan. Usulan Penelitian Perguruan Tinggi. Bandung: Universitas Pendidikan Indonesia

[15] Fraden, J. (2004). Handbook of Modern Sensor. San Diego: Advanced Monitor Corporation.

[16] Yu, F. T., \& Yin, S. (2002). Fiber Optic Sensors. New York: Marcel Dekker.

[17] Rabus, D. (2007). Ring Resonators: Theory and Modeling. Dalam D. G. Rabus, Integrated Ring Resonators: The Compendium (hal. 3-40). Springer.

[18] Yin, S., \& Ruffin, P. (2006). Fiber Optics Sensors. Dalam M. Akay, Wiley Encyclopedia of Biomedical Engineering. John Wiley \& Sons, Inc.

[19] Mulyanti, B., Menon, P. S., Shaari, S., Hariyadi, T., Hasanah, L., \& Haroon, H. (2014). Design and Optimization of Coupled Microring Resonators. Sains Malaysiana, 247-252.

[20] Muhammadi, A., Sugesti, E. S., \& Mahmudin, D. (2015, Desember). Simulasi Filter Optik Single Microring Resonator Sebagai Optical Add Drop Multiplexer. e-Proceeding of Engineering, 2(3), 7308-7314.

[21] Haroon, H., Shaari, S., Menon, P. S., Majlis, B. Y., Razak, H. A., \& Bidin, M. 
(2012). Effect of low temperature on thee Fabrication of microring resonator by wet etching. American Journal of Applied Science, 1922-1928.

[22] Schweb, O. (2004). Transmission, group delay and dispersion in single-ring optical resonators and add/drop filters-a tutorial overview. J. Lightwave Technol., 13801394.

[23] Zhang, X., Jian, J., Jin, H., \& Xu, P. (2017). Nested Microring Resonator with a Doubled Free Spectral Range for Sensing Application. Front. Optoelecron, 144-150.

[24] Chao, C.-Y., Fung, W., \& Guo, L. J. (2006). Polymer Microring Resonators for Biochemical Sensing Applications. IEEE Journal of Selected Topics in Quantum Electronics, 12, 134-142.

[25] Molecular Devices. (2011, Maret 16). Center Wavelength $(\mathrm{CW})$ and Full Width at Half Maximum (FWHM) filter numbers. Dipetik September 11, 2018, dari Molecular Devices: http://mdc.custhelp.com/app/answers/deta il/a_id/19235/ /center-wavelength$\% 28 \mathrm{cw} \% 29$-and-full-width-at-halfmaximum-\%28fwhm\%29-filter-numbers

[26] Lee, B., \& Jeong, Y. (2002). Interrogation Techniques for Fiber Grating Sensors and the Theory of Fiber Gratings. Dalam F. T. Yu, \& S. Yin, Fiber Optic Sensors (hal. 310-311). New York: Marcel Dekker, Inc.

[27] Mohamed, M., Li, Z., Chen, X., Mickelson, A., \& Shang, L. (2011). Modeling and Analysis of Micro-Ring Based Silicon Photonic Interconnect for Embedded Systems. IEEE ACM IFIP International Conference (hal. 227-2366). Taipei: ACM Press.
[28] Eklund, E. J., \& Shkel, A. M. (2005). Performance Tradeoffs in MEMS Sensors with High-Finesse Fabry-Perot Interferometry Detection. NSTI-Nanotech, 3, 533-536.

[29] Passaro, V. M., Dell'Olio, F., \& Leonardis, F. D. (2007). Ammonia Optical Sensing by Microring Resonators. Sensors, 2741-2749.

[30] Bogaerts, W., Heyn, P. D., Vaerenbergh, T. V., Vos, K. D., Selveraja, S. K., Claes, T., et al. (2012). Silicon Microring Resonators. Laser Photonics Reviews, 4773.

[31] Kim, Y., Lee, Y. J., Hong, S., Moon, K., \& Kwon, S.-H. (2018, September 4). Photonic Crystal Cavity with a Thin LowIndex Layer for Silicon-Compatible Nanolight Source. applied sciences.

[32] Haynes, W. M. (Penyunt.). (2015). CRC Handbook of Chemistry and Physics (96th ed.). Boca Raton, Florida: CRC Press/Taylor and Francis.

[33] Shahriari, M. R., \& Ding, J. (1994). Doped Sol-gel Films for Fiber Optic Chemical Sensors. Dalam L. C. Klein, Sol-gel Optics: Processing and Applications (hal. 282). Boston: Kluwer Academic.

[34] Cao, W., \& Duan, Y. (2005). Optical fiberbased evanescent ammonia sensor. Sensors and Actuators B 110, 252-259. 